\title{
MULTI-LEVEL OPTIMIZATION OF AN AUTOMOTIVE CLOSED-LOOP SUPPLY CHAIN NETWORK WITH INTERACTIVE FUZZY PROGRAMMING APPROACHES
}

\author{
Abdullah YILDIZBAŞI ${ }^{1}$, Ahmet ÇALIK ${ }^{2}$, Turan PAKSOY ${ }^{3 *}$, \\ Reza ZANJIRANI FARAHANI ${ }^{4}$, Gerhard-Wilhelm WEBER ${ }^{5}$ \\ ${ }^{1}$ Industrial Engineering, Yildirım Beyazıt University, Ankara, Turkey \\ ${ }^{2}$ Logistics Management, KTO Karatay Universitesi, 42020 Konya, Turkey \\ ${ }^{3}$ Department of Industrial Engineering, Selçuk University, Konya, Turkey \\ ${ }^{4}$ Department of Management, Kingston Business School, Kingston Hill, \\ Kingston Upon Thames, Surrey, United Kingdom \\ ${ }^{5}$ Intitute of Applied Mathematics, Middle East Technical University, 06800 Ankara, Turkey
}

Received 03 June 2015; accepted 23 October 2016

\begin{abstract}
Closed-Loop Supply Chain (CLSC) management has attained appreciable attention over the last few years. CLSC management allows companies to manage their recovery and recycling activities of end products. Due to the latest developments in the world, producers are responsible for the collection, refurbishing, repairing and disassembly of end products at the end of their lives. This paper develops a mixed-integer CLSC model that is inspired by the automotive industry. In this model, we consider three Decision Makers (DM): Plant, Dismantler Center and Customer. Each DM has individual objectives and is responsible for only its own objective function under same constraints. In order to tackle the trade-offs among the objectives, we used four different Interactive Fuzzy Programming (IFP) approaches. The applications of the model and solution techniques are investigated in conjectural data. The paper ends with a conclusion and a call for future studies.
\end{abstract}

Keywords: automotive industry, closed-loop supply chain, interactive fuzzy programming, multilevel programming, mixed-integer linear programming.

JEL Classification: C6, C61, D3, L6, L62, R4, D8.

\section{Introduction}

As the environmental concerns become more important in manufacturing industry, Supply Chain Management (SCM) has gained noticeable attention in the literature. SCM can be defined as an integrated system including the purchasing, manufacturing, holding, distribu-

${ }^{\star}$ Corresponding author. E-mail: tpaksoy@yahoo.com 
tion and manage of products (Bilgen 2010). Supply chain structures deal with issues such as effective use of limited resources, development of environmentally friendly production methods, government regulations and meeting the customer's expectations. Environment awareness and management of these environmental concerns are one of the most important subjects of SCM. At this point Green Supply Chain Management (GSCM) has appeared as an organizational doctrine which helps establishments and their participants to achieve corporate profit and market-share objectives by decreasing environmental impacts and risk while increasing ecological efficacy (Azevedo et al. 2011).

As an implementation of GSCM the design of the CLSC network that involves both forward and reverse flows, has gained more attention with the increasing developments. A well-organized supply chain helps the managers to get more accurate and fast decisions in the competitive and dynamic marketplace. By the usage of supply chain network design, a various number of questions can be answered: What the optimal capacities of facilities are, what the optimal number of facilities is, where the locations of facilities are and what the optimal flow between them is.

This study was inspired by an automotive industry which is including a number of significant issues related fundamentally to its effect on the environment. Vehicles effect the environment from production to the end of life. Automobile production process and use caused burdens on the environment such as consumption of resource and energy, greenhouse gases, hazardous waste creation, and disposal at the end of their lives (Kanari et al. 2003). A Vehicle includes different materials such as ferrous and non-ferrous materials. Ferrous materials, which are perfect candidates for recycling, are the primary component of a vehicle, accounting for $71 \%$ of a vehicle's weight. Other significant materials involved in the vehicle are non-ferrous metals, plastics, rubber, glass and liquids, contributing 7\%, 8\%, 5\%, 3\%, and 2\%, respectively (Harraz, Galal 2011).

Legislative measures that promote the recycling of a large percentage of ELVs are enforced in an increasing number of countries (Vidovic et al. 2011). Today, the East Asian countries, European Union countries, the United States and many other countries legislatively force producers to take care of their ELVs. ELVs are sent from collection centers to dismantler centers, which remove reusable and refurbishing parts such as the fuel tanks, tires, engines, radiator, catalytic converter, transmission, batteries, and air bags. Some of these parts are reusable so they removed from the cars for the values and the rest of the parts are removed because the shredder requires (Staudinger et al. 2001). After this process, the shredding machine chops the car remains into pieces of various sizes, which are separated with different separation technologies (i.e., eddy curry) into 3 main categories (Williams et al. 2007). These are: i) Ferrous materials (all iron and steel, except stainless steel), ii) Non-ferrous materials (both metals and non-metals), iii) After Shredding Residue (ASR). The ferrous materials are sold at a about $\$ 150$ per metric ton, the non-ferrous materials are sold at about $\$ 600$ per metric ton and finally ASR is landfilled in an EPA subtitle D landfill at a variable price, depending on the density or geographic region (Kumar, Sutherland 2008).

The main aim of this study is to develop a multi-level CLSC model which is inspired by the automotive industry. Considering the material flow from parts to the end product in the automotive industry, we design a CLSC network taking into consideration the material flow 
of the whole network. Thereby our study gives a discussion on how the heterogeneous flow in the network is transformed to the homogenous flow by a weight ratio mechanism. As another contribution of this study, we consider a decentralized CLSC model which consists of three different DMs' goals. In the literature, most of the papers consider the decentralized decision making for the forward or reverse supply chains. There are only a few studies dealing with the decentralized decision making problem in the closed-loop network design (Paksoy, Özceylan 2013; Zhou et al. 2013). In this paper, effects of some IFP approaches are investigated in decentralized decision making for CLSC. These investigated IFP approaches can be divided into two categories according to the relationship between DMs. The DMs choose either cooperative or non-cooperative behaviors to help them reach their goals. In addition, for decision making problems in the decentralized structures, cooperative behaviors can be more meaningful. From the perspective of a decentralized CLSC, our manuscript focuses on investigating the effects of communication among DMs. Firstly, we assumed that there is no cooperation between the DMs as a non-cooperative strategy and applied three IFP approaches respectively: Zimmermann (1978); Selim and Ozkarahan (2008); Torabi and Hassini (2008). Then, we assumed that all the DMs are implementing a cooperative strategy and then applied the Sakawa and Nishizaki (2002) approach to the developed model. A summary of the numerical experiment's results show that the DMs can obtain higher satisfaction levels with a cooperative strategy.

The remaining part of the paper is designed as follows: Part 1 shows relevant literature review. Part 2 describes the problem, introduces the proposed modeling approach for the CLSC and mathematical formulations. Computational results are represented for a number of scenarios to validate the pertinence of the model in Part 3. Finally, in Part 4, some final remarks are made and future studies suggested.

\section{Literature review}

CLSC literature is very broad in scope and thus in this section, we focused on CLCS models that are regarding to the automotive industry and published model with IFP approaches.

Schultmann et al. (2006) considered the ELVs treatment practiced in the automotive industry of Germany. The objective of the study was to increase the recycling ratio by reprocessing selected specific material. They suggested different options for a CLSC, focusing on the handling of the reverse flows and reintegrating them into their authentic supply chains. Williams et al. (2007) analyzed sensitivity of the recyclers regarding the installation or reprocessing decisions based on the different rates of ferrous and non-ferrous materials of ELVs in their study. They proposed a recycling planning model for automotive shredders to make short-term tactical decisions. They used a mixed-integer programming model to decide whether to combine materials for shipment. Contrary to current criticism, different scenarios were developed and tested in their study. Tang and Xie (2007) proposed a reverse logistic network problem model which consists of customers, collection centers, repair centers and plants. They presented a genetic-algorithm based heuristic to minimize the cost of operations. Numerical results showed that their proposed model approach outperformed other models. 
Salema et al. (2007) presented a mixed-integer mathematical model for a reverse flow. The aim of the model was to minimize the total cost. They considered capacity limits, collections, multi-product management and uncertainty on product demands for reverse logistics network design. Finally, the model was tested with the numerical examples. Qu and Williams (2008) proposed a non-linear programing model to address the automotive reverse production planning and pricing problem. They consider the price of contiguous shredders individually, and compare two bulk pricing strategies in three different metals. Cruz-Rivera and Ertel (2009) proposed a reverse logistics network design for the ELVs collection problem in Mexico. In this study, collection facilities are assumed to perform recall, decontamination and dismantling operations. They decided the locations of ELV collection facilities by the anticipated facility location problem model.

Baenas et al. (2011) investigated battery industries in the Midwest of the state of Sao Paulo and describe a reverse logistic chain in their study. As a result of research involving large, medium and small manufacturers, environmental awareness and recycling activities are more concerned by the large and medium sized manufacturers. In addition, a reverse logistic is proposed for small size manufacturers that create actions aimed to protect the environment. Sasikumar and Haq (2010) aimed to proposed a mixed-integer non-linear programming model for maximizing the profit of a multi-echelon reverse logistic network. They applied the model on a truck tire remanufacturing process for the secondary market in Indian automotive industry which is a real-life case study. In addition, a sensitivity analysis was used to determine the maximum allowable distance between the centers. Finally they concluded that using re-treading tire is a better way to reduce cost. Zarei et al. (2010) designed a reverse logistic network for efficient management of the whole ELV recovery process. The distribution of new vehicles and collection of the ELVs are considered simultaneously in the model. They developed a mathematical model which aims to minimize the set-up costs and transportation costs.

Vidovic et al. (2011) proposed a modelling approach for the collection of ELVs by defining optimum locations for collection points. They proposed division of service zones into subzones or subsets of demand locations to maximize the collection of ELVs while minimizing collection fails. In order to make the result of this study more realistic, the model was illustrated in Belgrade city. Vahdani et al. (2012) developed a new modelling approach to establish a reliable network design of plants in closed loop supply chains under uncertainty. They illustrated this CLSC model on the iron and steel industry. The model is multi-echelon, multi-product, multi-facility and multi-supplier, which can cause high complexity for reverse logistic network designs. For this purpose, they proposed a new mixed solution methodology. Finally, the numerical experiments are given to demonstrate the significance of the presented model as well as the solution approach.

Mahmoudzadeh et al. (2013) developed a third party reverse logistic network for ELV management in Iran. They proposed a mixed-integer linear programming model for ELVs to determine the optimal locations of scrap yards as well as their optimal allocations and material flows. The objective function of the model is to minimize the total cost, including fixed, operation and transportation costs. The model was tested on two different scenarios and categorized in three quality levels based on different output materials streams. In conclusion, 
a specialization trend was observed in the distribution process which was that most scrap yards are opened with serving only first and second quality level products.

The interactive fuzzy multi-objective programming approach suggested by Sakawa et al. (1998) is an approach based on the collaboration DMs. Among decision-makers it is accepted that there is a hierarchical sequential structure and it is aimed at obtaining the optimal solution regarding the degree of satisfaction of the DMs. The high-level DMs determine the minimum satisfaction level for themselves by preserving the satisfaction degrees between them and other DMs. Minimum satisfaction levels have been updated based on subjective judgments of their methods. In this study, it is intended to obtain an analytical solution to update the minimum satisfaction level which takes into account the opinions of DMs.

Abd El-Wahed and Lee (2006) studied on a multi-objective transportation problem and they used an interactive fuzzy goal programming approach to determine the preferred compromise solution. In order to solve the fuzzy multi-objective transportation problem, an interactive fuzzy multi-objective linear programming (i-FMOLP) model was developed by Liang (2006). The proposed i-FMOLP method aims to simultaneously minimize the total distribution costs and the total delivery time. By the way i-FMOLP method helps the DM until a satisfactory solution is obtained.

Selim and Ozkarahan (2008) presented a linear programming model which has different objectives to address the Supply Chain networks distribution problem. The model has two conflict objective functions and the goal of the model is to optimize these objective functions as well as decide the locations and capacity levels of facilities, and storages to deliver products to retailers at the minimum cost while satisfying the desired service level of retailers. So they presented a novel interactive fuzzy goal programming model to determine the acceptable solution.

Torabi and Hassini (2008) developed a multi-objective possibilistic mixed-integer linear programming model based upon the Supply Chain model. The aim of their model is to consider different conflicting objectives simultaneously. They developed a two-phase IFP approach and for the second-phase they offered a new interactive fuzzy approach to find an efficient compromise solution.

Pishvaee and Torabi (2010) proposed a multi-objective possibilistic optimization model for a CLSC network. An interactive fuzzy solution approach was developed for solving the proposed possibilistic optimization model. Selim et al. (2008) used a fuzzy goal programming (FGP) approach to the collaborative production-distribution planning problems in both centralized and decentralized SC structures.

Zarandi et al. (2011) proposed a CLSC network design problem which assumes forward and backward flow objectives. The objective of the paper is to emphasize the role of considering reverse parameters in the design of a CLSC network and to present how results change from when sub-problems are considered individually. Zhou et al. (2013) focus on managing manufacturing-remanufacturing conflict from the perspective of the Original Equipment Manufacturer (OEM) in a decentralized CLSC. The main differences between this model and others is that the original equipment manufacturers can select a centralized or decentralized control mode to manage the plant's manufacturing and remanufacturing activities before 
the supplier prices the new component. They analyze the optimal decisions and compare the profits of OEMs under the centralized and decentralized modes.

Paksoy and Özceylan (2013) presented the pioneering paper for applying the IFP to the CLSC problem. Their study does not include a new IFP approach but they applied Sakawa and Nishizaki's (2002) approach to their hypothetical CLSC problem. Computational experiments are made for the proposed CLSC model which is inspired by the automotive industry and these IFP approaches are compared to develop some managerial implications for CLSC managers.

Mirakhorli (2014) proposed a fuzzy bi-objective reverse logistics network design problem. They used an interactive fuzzy multi-objective linear programming method for the solution. This method aims to minimize the total delivery time and total cost of the system simultaneously. Subulan et al. (2015a) have proposed a multi-level, multi-part and multiobjective Fuzzy CLSC model which has different priorities. Rather than cost or profitability based multi-objective CLSC models, it is aimed at maximizing the total return products in the developed model. Solving the developed problem is attempted using fuzzy goal programming. Also, a new approach is developed by taking the weighted geometrical mean of each fuzzy goal to observe the acceptable success level. The proposed approach is modelled by inspiring from lead/battery industry in Turkey. Finally, the model is tested with various scenario analyses.

Subulan et al. (2015b) presented a holistic mixed-integer linear programming model that is inspired by the tire industry. Based on the developed model, reverse activities are considered simultaneously and include multi-level, multi-product, multi-objective and multiechelon. Eco-indicator 99, which is called a damage-oriented method, is used to analyze the environmental impact. An Interactive Fuzzy Goal Programming approach is used to solve the proposed model and experimental design is developed based on the Taguchi design and is used to test the model.

\section{Problem definition and modelling}

In this part, a novel mixed integer CLSC model is proposed to develop a CLSC network design inspired by the Turkish automotive industry. First, the assumptions about the identified problems are explained, and then the mathematical formulations and numerical data are addressed.

\subsection{Problem definition}

A novel mixed integer CLSC model based on inspiration from the automotive industry in Turkey is proposed in which forward and reverse flows and their mutual interactions are considered simultaneously. The former are used to purchase sub-parts, assemble them to vehicles and deliver them to customers, whereas the latter are used for collection, dismantling, and refurbishing or disposal of the same products. The network is structured as a five forward supply chain, namely: raw-material suppliers, suppliers, plants, distributors, and customers. Similarly, a four structure is considered for the reverse flow, namely: collection centers, dismantler centers, refurbishing centers, and final disposal locations. 
The network includes raw material suppliers that provide different types raw materials to suppliers. A number of suppliers provide different parts/components with a certain utilization number to plants in which they are transformed into the same number of products. Obtained parts or components are assembled in plants, and after that assembled products are transferred to distributors through the customers. Opened plants, retailers, collection centers and dismantler centers are restricted with a pre-defined number in each period. Reverse flow begins with the collection of the end of life vehicles from end users/customers.

The used products, which do not meet quality requirements, have out of date technology, are damaged or inconsumable, are collected from customers sent through chain. It is assumed that the demand for each product collected from customer zones is known and fully satisfied. Products can be transported to dismantler centers after the collection process. After collected products received by dismantler center, they are classified with respect to refurbishing, resell, reproduction and disposal alternatives. Some of returned products whose conditions are suitable for reproduction are dismantled until ferrous and nonferrous materials, parts and/or components are obtained. After dismantled products, the rest of the materials which are called automotive shredder residue (ASR) are sent for disposal. When the product has been dismantled, ferrous and nonferrous materials are separated from other parts and the other parts/components are cleaned and tested. After the dismantling process, the dismantler center has two types of parts/components, which are reusable and remanufacturing parts. Cleaned and tested dismantled products are separated into two groups. The first group of parts/components are transported to refurbishing centers and the rest of parts/components are transported to the customer as a used part/component. The last group is called bulk product which includes ferrous and nonferrous products sent to the raw material suppliers. Parts are restored to obtained new ones by the refurbishing process. The new parts are transported to plants and used for manufacturing products in the next period. An enterprise can supply necessary parts in two ways. Purchasing the necessary parts from external suppliers is the first way and the other way is getting them by dismantling and refurbishing the used products that are in good shape for reproduction. The refurbished parts are comparable to the newly manufactured parts. In this model customers have the same situation too. Customers can purchase parts with two ways, one is purchasing required parts from an OEM which supplies this model, and the other option is purchasing from a dismantler center as second hand. There are mainly four kinds of cost: transportation, purchasing, refurbishing, and fixed costs of potential plants, retailers, collection centers and dismantler centers (see Fig. 1).

The proposed model has the features of multi-level programming. The model has three different DMs and each one has their individual objectives. The DM, who is at the upper level of two levels, is the plant/manufacturer and there are two DMs at the lower level, who are the dismantlers and customers, respectively. The objective function of the plants' is to minimize the total costs of the system and to decide the transported quantities and the parts to be purchased from suppliers or refurbishing centers. The second DM, which is called dismantler center must also decide on cost. Transported quantities of bulk, reusable and remanufacturing products, and collected, and disposed quantities of used products must be optimized in order to determine the total cost of the dismantling system. The third DM, which is called the customer, must decide in terms of cost to buy original 


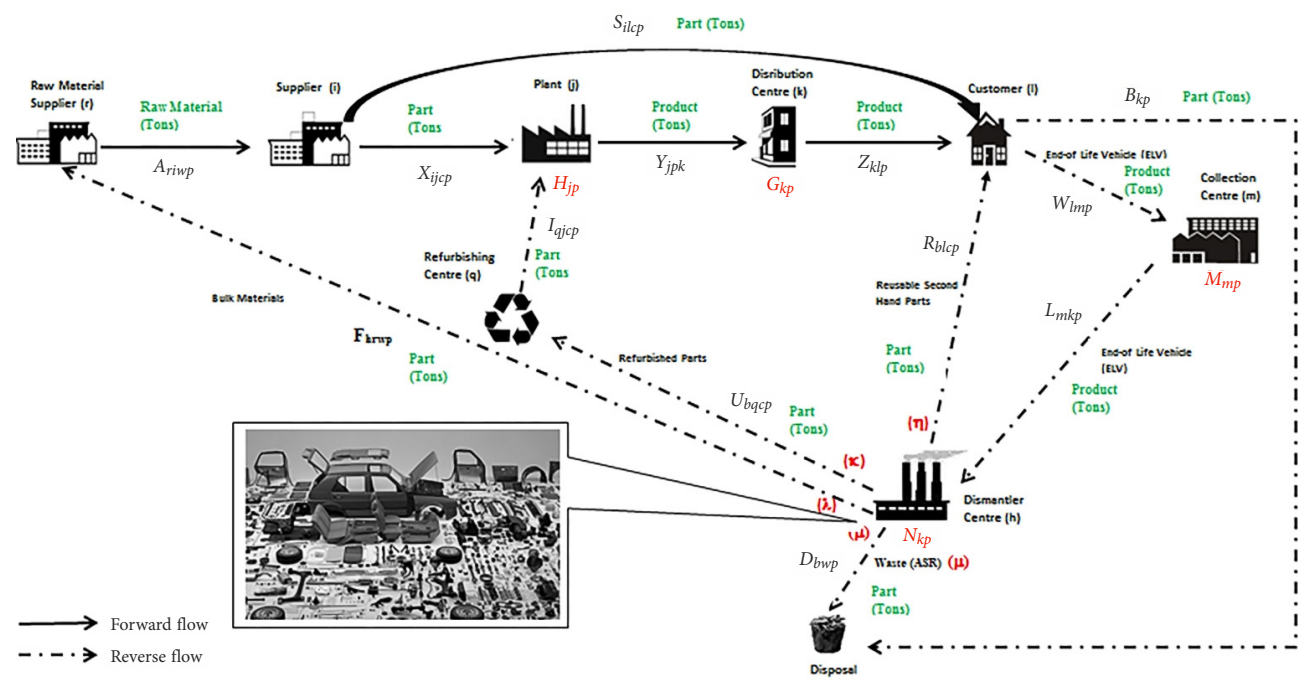

Fig. 1. Designed FSC, RSC and CLSC Network Design Model

parts/components or dismantled reusable (secondhand) parts/components (Demirel, Gökcen 2008; Neto et al. 2008; Wang, Hsu 2010; Özceylan, Paksoy 2012; Özceylan et al. 2014; Farahani et al. 2014).

Further assumptions about the problem are as follows:

- The demand for each product is for multi-periods, is deterministic, and must be fully satisfied.

- The cost of transportation, purchasing, refurbishing, and opening facilities, are fixed and deterministic.

- Transportation, purchasing, refurbishing, and fixed costs are deterministic and known a priori.

- Collection, disposal, and disassembly rates are known a priori.

- No waste is assumed during the part production from raw material.

- Each reversed product (car) weight is assumed to be 1 ton.

- There is no difference between the original parts sent from suppliers to plants and used parts renewed by refurbishing centers.

- The sum of the percentage of parts sent from the dismantler center to the other centers, (such as refurbishing center, raw material suppliers, customers, or disposal) are equal to 1 . So $\eta+\kappa+\lambda+\mu=1$.

- Transportation costs are not changed by part/component size and type.

- The capacities of all facilities both forward and reverse are limited and fixed.

- Inventory and shortages are not allowed.

Customer demands actually represent different customers than expressed in the assumptions. For example, the plant is the main producer in the model, but is also described as a 
customer demand from the refurbishing center. In the same way end users can be described as customers. In addition to this, raw material suppliers are also the customers of dismantler centers and have a certain level of demand. The collection centers are designed as a center of collection of the ELVs and after that they are sent to the dismantler centers. Dismantler centers can be defined as the center of ELV separated into parts.

\subsection{Model formulation}

The mixed-integer mathematical model, which provides all of the above-mentioned decisions and assumptions, and its formulation are presented below.

\section{Sets}

$r$ - the index of material suppliers,

$i$ - the index of suppliers,

$j$ - the index of plants,

$k$ - the index of retailers,

$l$ - the index of customers,

$m$ - the index of collection centers,

$h$ - the index of dismantler centers,

$q$ - the index of refurbishing centers,

$c$ - the index of parts,

$p$ - the index of periods,

$w$ - the index of raw materials;

\section{Parameters}

$v_{r w p}$ - production capacity of the $r$ th raw material supplier for raw material $w$ in period $p$ (ton),

$a_{i c p}-$ production capacity of the $i$ th supplier for part $c$ in period $p$ (ton),

$b_{j p} \quad$ - production capacity of the $j$ th plant in period $p$ (ton),

$c_{k p} \quad$ - production capacity of the $k$ th retailer in period $p$ (ton),

$d_{l p} \quad$ - demand of customer $l$ in period $p$ (ton),

$d_{l c p} \quad$ - demand of customer $l$ for part $c$ in period $p$ (ton),

$e_{m p}-$ production capacity of the $m$ th collection center in period $p$ (ton),

$f_{h p}$ - production capacity of the $h$ th dismantler center in period $p$ (ton),

$g_{q c p}$ - production capacity of the $q$ th refurbishing center for part $c$ in period $p$ (ton),

$\Delta_{r i}$ - distance from raw material supplier $r$ to supplier $i(\mathrm{~km})$,

$\Delta_{i j} \quad$ - distance from supplier $i$ and plant $j(\mathrm{~km})$,

$\Delta_{j k} \quad$ - distance from plant $j$ to retailer $k(\mathrm{~km})$,

$\Delta_{k l} \quad$ - distance from retailer $k$ to customer $l(\mathrm{~km})$,

$\Delta_{l m}$ - distance from customer $l$ to collection center $m(\mathrm{~km})$,

$\Delta_{m h}$ - distance from collection center $m$ to dismantler center $h(\mathrm{~km})$,

$\Delta_{h l}$ - distance from dismantler center $h$ to customer $l(\mathrm{~km})$,

$\Delta_{h q}$ - distance from dismantler center $h$ to refurbishing center $q(\mathrm{~km})$,

$\Delta_{h r}$ - distance from dismantler center $h$ to raw material supplier $r(\mathrm{~km})$,

$\Delta_{h} \quad$ - distance from dismantler center $h$ to disposal $(\mathrm{km})$, 
$\Delta_{q j} \quad$ - distance from refurbishing center $q$ to plant $j(\mathrm{~km})$,

$\Delta_{i l} \quad$ - distance from supplier $i$ and customer $l(\mathrm{~km})$,

$r w_{c}$ - the unit ratio of one part $c$ in final product,

$\alpha_{j p} \quad-$ fixed cost of opening of plant $j$ in period $p(\$)$,

$\beta_{k p} \quad$ - fixed cost of opening of retailer $k$ in period $p(\$)$,

$\gamma_{\mathrm{mp}} \quad$ - fixed cost of opening of collection center $m$ in period $p(\$)$,

$\theta_{\mathrm{hp}} \quad$ - fixed cost of opening of dismantler center $h$ in period $p(\$)$,

$t \quad$ - unit shipping cost $\left(\$ /\right.$ ton $\left.^{\star} \mathrm{km}\right)$,

poe $_{i c}$ - price of original spare parts (\$/ton),

pue $_{h c}$ - price of second hand (used) spare parts (\$/ton),

$\pi_{i c} \quad-$ unit purchasing cost of part $c$ from supplier $i$ (\$/ton),

$\rho_{q c} \quad$ - unit refurbishing cost of part $c$ at refurbishing center $q$ (\$/ton),

$r d e_{c}-$ revenue from each part which is sent from dismantler center to customers (\$/ton),

$\mathrm{rre}_{c}$ - revenue from each part which is sent from dismantler center to refurbishing center (\$/ton),

$r_{b m}$ - revenue from bulk material which is sent from dismantler center to raw material supplier (\$/ton),

$c_{d}-$ disposal cost (\$/ton),

$H_{p}$ - maximum available number of plants in period $p$ (quantity),

$G_{p}$ - maximum available number of retailers in period $p$ (quantity),

$M_{p}$ - maximum available number of collection centers in period $p$ (quantity),

$N_{p}$ - maximum available number of dismantler centers in period $p$ (quantity),

$\eta$ - percentage of part which is sent from dismantler center to customer,

$\kappa$ - percentage of part which is sent from dismantler center to refurbishing center,

$\lambda$ - percentage of part which is sent from dismantler center to raw material supplier,

$\mu$ - percentage of part which is sent from dismantler center to disposal;

\section{Decision variables}

$A_{\text {riwp }}$ - amount of raw material $w$ sent from raw material supplier $r$ to supplier $i$ in period $p$ (ton),

$X_{i j c p}$ - amount of part $c$ sent from supplier $i$ to plant $j$ in period $p$ (ton),

$Y_{j k p}$ - amount of product sent from plant $j$ to retailer $k$ in period $p$ (ton),

$Z_{k l p}$ - amount of product sent from retailer $k$ to customer $l$ in period $p$ (ton),

$W_{l m p}$ - amount of used product sent from customer $l$ to collection center $m$ in period $p$ (ton),

$L_{m h p}$ - amount of used product sent from collection center $m$ to dismantler center $h$ in period $p$ (ton),

$R_{\text {hlcp }}$ - amount of part $c$ sent from dismantler center $h$ to customer $l$ in period $p$ (ton),

$U_{h q c p}$ - amount of part $c$ sent from dismantler center $h$ to refurbishing center $q$ in period $p$ (ton),

$F_{h r w p}$ - amount of raw material $w$ sent from dismantler center $h$ to raw material supplier $r$ in period $p$ (ton),

$D_{h w p}$ - amount of raw material $w$ sent from dismantler center $h$ to disposal in period $p$ (ton), 
$I_{q j c p}$ - amount of part $c$ sent from refurbishing center $q$ to plant $j$ in period $p$ (ton),

$S_{i l c p}$ - amount of part $c$ sent from supplier $i$ to customer $l$ in period $p$ (ton),

$H_{j p} \quad$ - if plant $j$ is open in period $p, 1$; otherwise, 0 ,

$G_{k p} \quad$ if retailer $k$ is open in period $p, 1$; otherwise, 0 ,

$M_{m p}$ - if collection center $m$ is open in period $p, 1$; otherwise, 0 ,

$N_{h p}$ - if dismantler center $h$ is open in period $p, 1$; otherwise, 0 ;

\section{Objective function 1 (Decision Maker 1; Plant)}

minimize

$$
\begin{aligned}
& t \cdot\left(\sum_{r} \sum_{i} \sum_{w} \sum_{p} A_{r i w p} \cdot \Delta_{r i}+\sum_{i} \sum_{j} \sum_{c} \sum_{p} X_{i j c p} \cdot \Delta_{i j}+\sum_{j} \sum_{k} \sum_{p} Y_{j k p} \cdot \Delta_{j k}+\right. \\
& \left.\sum_{k} \sum_{l} \sum_{p} Z_{k l p} \cdot \Delta_{k l}+\sum_{q} \sum_{j} \sum_{c} \sum_{p} I_{q j c p} \cdot \Delta_{q j}\right)+ \\
& \sum_{i} \sum_{j} \sum_{c} \sum_{p} X_{i j c p} \cdot \pi_{i c}+ \\
& \sum_{q} \sum_{j} \sum_{c} \sum_{p} I_{q j c p} \cdot \rho_{q c}+ \\
& \sum_{j} \sum_{p} H_{j p} \cdot \alpha_{j p}+\sum_{k} \sum_{p} G_{k p} \cdot \beta_{k p} .
\end{aligned}
$$

Objective function 2 (Decision Maker 2; Dismantler Center)

maximize

$$
\begin{aligned}
& \left(\sum_{c} r d e_{c} \cdot \sum_{h} \sum_{l} \sum_{c} \sum_{p} R_{h l c p}+\sum_{c} r r e_{c} \cdot \sum_{h} \sum_{q} \sum_{c} \sum_{p} U_{h q c p}+\sum_{w} r b m_{w} \cdot \sum_{(5)} \sum_{r} \sum_{w} \sum_{p} F_{h r w p}\right)- \\
& \left(t \cdot \left(\sum_{l} \sum_{m} \sum_{p} W_{l m p} \cdot \Delta_{l m}+\sum_{m} \sum_{h} \sum_{p} L_{m h p} \cdot \Delta_{m h}+\sum_{h} \sum_{q} \sum_{c} \sum_{p} U_{h q c p} \cdot \Delta_{h q}+\right.\right. \\
& \left.\sum_{h} \sum_{r} \sum_{w} \sum_{p} F_{h r w p} \cdot \Delta_{h r}+\sum_{h} \sum_{w} \sum_{p} D_{h w p} \cdot \Delta_{h}\right)+ \\
& \sum_{m} \sum_{p} M_{m p} \cdot{ }_{m p}+\sum_{h} \sum_{p} N_{h p} \cdot{ }_{h p}+ \\
& \left.\sum_{w} c d_{w} \cdot \sum_{h} \sum_{w} \sum_{p} D_{h w p}\right) .
\end{aligned}
$$

Objective function 3 (Decision Maker 3; Customer)

minimize

$$
\begin{aligned}
& t \cdot\left(\sum_{h} \sum_{l} \sum_{c} \sum_{p} R_{h l c p} \cdot \Delta_{h l}+\sum_{i} \sum_{l} \sum_{c} \sum_{p} S_{i l c p} \cdot \Delta_{i l}\right)+ \\
& \sum_{i} \sum_{l} \sum_{c} \sum_{p} S_{i l c p} \cdot p o e_{i c}+\sum_{h} \sum_{l} \sum_{c} \sum_{p} R_{h l c p} \cdot p u e_{h c} \cdot
\end{aligned}
$$

subject to

$$
\sum_{i} A_{\text {riwp }} \leq v_{\text {rwp }}, \quad \forall_{r, w, p} \text {; }
$$




$$
\begin{aligned}
& \sum_{l} S_{i l c p}+\sum_{j} X_{i j c p} \leq a_{i c p} \\
& \sum_{k} Y_{j k p} \leq b_{j p} \cdot H_{j p} \\
& \forall_{i, c, p} \\
& \forall_{j, p} ; \\
& \sum_{l} Z_{k l p} \leq c_{k p} \cdot G_{k p}, \quad \forall{ }_{k, p} \text {; } \\
& \sum_{h} L_{m h p} \leq e_{m p} \cdot M_{m p} \text {, } \\
& \forall_{m, p} \text {; } \\
& D_{h w p}+\sum_{l} R_{h l c p}+\sum_{q} U_{h q c p}+\sum_{r} F_{h r w p} \leq f_{h p} \cdot N_{h p}, \quad \forall_{h, c, w, p} ; \\
& \sum_{j} I_{q j c p} \leq g_{q c p} \text {, } \\
& \sum_{k}^{j} Z_{k l p} \geq d_{l p} \\
& \forall_{q, c, p} ; \\
& \forall_{l, p} ; \\
& \forall_{l, c, p} ; \\
& \forall_{p} ; \\
& \forall_{p} ; \\
& \forall_{p} ; \\
& \forall p ; \\
& \forall_{i, p} ; \\
& \sum_{i} X_{i j c p}+\sum_{q} I_{q j c(p-1)}-r_{w c} \cdot \sum_{k} Y_{j k p}=0, \quad \forall_{j, p, c} ; \\
& \sum_{j} Y_{j k p}-\sum_{l} Z_{k l p}=0, \quad \forall k, p ; \\
& \sum_{k} Z_{k l p}-\sum_{m} W_{l m(p+1)}=0, \quad \forall \forall_{l, p} ; \\
& \sum_{i} S_{i l c p}+\sum_{h} R_{h l c p}-B_{l c(p+1)}=0, \quad \forall{ }_{l, p} ; \\
& \sum_{l} W_{l m p}-\sum_{h} L_{m h p}=0 \text {, } \\
& \forall_{m, p} \text {; } \\
& \sum_{c} r w_{c} \cdot \sum_{m} L_{m h p} \cdot \eta-\sum_{l} \sum_{c} R_{h l c p}=0, \quad \forall_{h, p} ; \\
& \sum_{c} r w_{c} \cdot \sum_{m} L_{m h p} \cdot \kappa-\sum_{q} \sum_{c} U_{h q c p}=0, \quad \forall{ }_{h, p} \text {; } \\
& \sum_{m} L_{m h p} \cdot \lambda-\sum_{r} \sum_{w} F_{h r w p}=0, \quad \forall{ }_{h, p} \text {; } \\
& \sum_{m} L_{m h p} \cdot \mu-\sum_{w} D_{h w p}=0, \quad \forall_{h, p} ; \\
& \sum_{h} U_{h q c p}-\sum_{j} I_{q j c p}=0, \quad \forall_{q, c, p} ;
\end{aligned}
$$




$$
\begin{array}{ll}
A_{r i w p} \geq 0, & \forall_{r, i, w, p} ; \\
X_{i j c p} \geq 0, & \forall_{i, j, c, p} ; \\
Y_{j k p} \geq 0, & \forall_{j, k, p} ; \\
Z_{k l p} \geq 0, & \forall_{k, l, p} ; \\
W_{l m p} \geq 0, & \forall_{l, m, p} ; \\
L_{m h p} \geq 0, & \forall_{m, h, p} ; \\
U_{h q c p} \geq 0, & \forall_{h, q, c, p} ; \\
F_{h r w p} \geq 0, & \forall_{h, r, w, p} ; \\
R_{h l c p} \geq 0, & \forall_{h, l, c, p} ; \\
S_{i l c p} \geq 0, & \forall_{i, l, c, p} ; \\
I_{q i c p} \geq 0, & \forall_{q, i, c, p} ; \\
D_{h w p} \geq 0, & \forall_{h, w, p} ; \\
H_{j p}, G_{k p}, M_{m p}, N_{h p}=\{0,1\}, & \forall_{j, k, m, h, p} .
\end{array}
$$

The model has three objective functions and each objective function has different components. The first objective function comprises four components: the cost of transportation (1), the cost of purchasing (2), the cost of refurbishing product parts (3), and the fixed costs associated with locating the plants and retailers, respectively (4). The second objective function has four components. The first component represents the maximization of revenue from dismantler parts which are sent from the dismantler center to other facilities (5). The second component represents the cost of transportation on some arcs of the network in the reverse chains (6). The third component shows the fixed costs associated with locating the collecting centers and dismantler centers, respectively (7) and the last component represents the disposal costs (8). The third objective function has two components. The first component represents the cost of transportation (9) and the second component represents the cost of purchased spare parts from different suppliers such as the dismantler center and the OEM supplier (10). Constraints (11-17) stipulate that the production and transportation amount must not exceed the capacity of raw materials suppliers, suppliers, plants, retailers, collection centers, dismantler centers, and refurbishing centers, respectively. Constraints (18) and (19) ensure that demands for each product and each part must fully be met. Constraints (20-23) limit the number of plants, retailers, collection centers and dismantler centers that can be opened. Constraints (24-34) are the balance equations for the forward and reverse part facilities: the quantities that enter to these facilities must be equal to the amount of products/ parts that leave the facilities. Lastly, constraints (35-47) ensure the non-negativity and binary restrictions on the decision variables. 


\section{Computational experiments}

In this section, computational experiments are carried out with the proposed model are presented using a hypothetical CLSC network problem.

\subsection{Description of data}

In this chapter, the validity and the applicability of the CLSC model was examined and have been tested in GAMS 24.0.1 package program with hypothetical data which is given in the previous section with the formulation of the mathematical model. Then a scenario analysis was performed to measure the effects of different parameter values on the system.

The network comprises five raw material suppliers, four suppliers, three plants, three distribution centers and six customers in the forward supply chain network. The reverse supply chain network includes two collection centers which are responsible for collecting the ELVs from customers, three dismantler centers, three refurbishing centers and a disposal. Suppliers provide five kinds of components that have different weight ratios, which, in turn, are converted into final products. It is assumed that the weight ratios of the components for this final product are given in Figure 2.

As a final product, an automobile is calculated in terms of tons and has been addressed in terms of total constituting parts of the final product. After the assembling the components in the specified ratio are obtained, the final products are delivered to customers (end users) through distribution centers. After the first period, the used products are collected from customers by collection centers. The products that are collected by collection centers are sent to the dismantler centers for dismantling operations.

If there is no important problem with the pieces obtained from dismantled products, some of used products are transported to the customers directly as second-hand parts. The rest of pieces in good condition and the pieces that could be used in production after renewal are transported to the renewal centers. After the renovation of these products, they are delivered to the plants. After dismantling usable and renewable pieces, the rest of the pieces (bulk material), such as chassis and so on, are transported to the raw material center to use as a raw material. These kind of materials meet the material requirements of

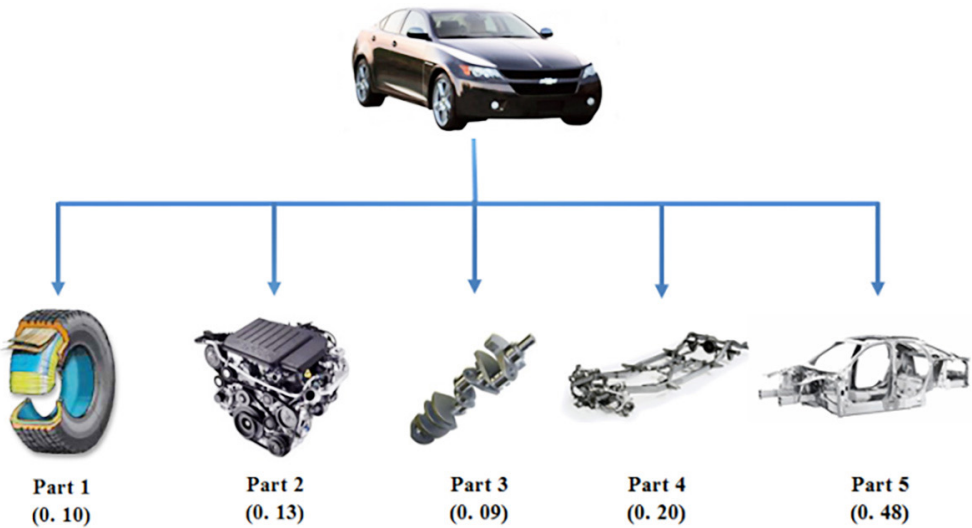

Fig. 2. Bill of material of the final product 
different sectors after different heat treatments at the raw material center. Finally, pieces, which are out of condition, and residuals, after decomposition and shredding, are transported to the residual center.

The unit transportation cost $(t)$ was accepted as 7 cents per ton-km which is calculated based on operating costs and contains salaries, wages, insurance, cost of fuel and operating supplies and depreciation (Özceylan, Paksoy 2012). The unit cost of purchasing raw materials $\left(\pi_{i c}\right)$ and unit cost of refurbishing $\left(\rho_{q c}\right)$ varies depending on the part type. Fixed operating costs of the plant, distribution center, collection center and refurbishing center also varies periodically. A fixed operating cost of the plant includes annual depreciation charge and opened and closed assembly lines scope of the project. The unit cost of purchasing and the unit cost of refurbishing also vary periodically. The ratio of the parts sent from dismantler centers to customers, refurbishing centers, raw material suppliers and disposal are $\eta:(0.35), \kappa:(0.25)$, $\lambda:(0.30), \mu:(0.10)$, respectively. All other data used in the illustrative example are generated randomly according to the uniform distribution and the related data of our computational experiments is given below (Table 1).

Table 1. The parameters used in illustrative example

\begin{tabular}{|l|c|}
\hline \multicolumn{1}{|c|}{ Parameters } & Limits \\
\hline Distance from raw material supplier and supplier & $100-300$ \\
\hline Distance between supplier and plant & $100-300$ \\
\hline Distance between distribution center and customer & $50-150$ \\
\hline Distance between customer and collection center & $25-175$ \\
\hline Distance between collection center and dismantler center & $100-300$ \\
\hline Distance between dismantler center and refurbishing center & $50-250$ \\
\hline Distance between dismantler center and raw material supplier & $50-350$ \\
\hline Distance between dismantler center and customer & $50-150$ \\
\hline Distance between dismantler center and disposal & $50-200$ \\
\hline Distance between refurbishing center and plant & $30-250$ \\
\hline Distance between supplier and customer & $150-600$ \\
\hline Capacity of raw material supplier & $4000-9000$ \\
\hline Capacity of supplier & $4000-9000$ \\
\hline Capacity of plant & $2000-5000$ \\
\hline Capacity of distribution center & $2000-5000$ \\
\hline Customer demand & $150-300$ \\
\hline Customer spare part demand & $50-150$ \\
\hline Capacity of collection center & $2000-4500$ \\
\hline Capacity of dismantler center & $1000-3000$ \\
\hline Capacity of refurbishing center & $3000-7000$ \\
\hline Number of plants that can be opened & 3 \\
\hline Number of distribution center that can be opened & 3 \\
\hline Number of collection center that can be opened & 2 \\
\hline Number of refurbishing center that can be opened & 3 \\
\hline & \\
\hline & \\
\hline
\end{tabular}




\subsection{Solution by the Zimmermann (1978)}

The pay-off table indicates the best values which are represented with the bold values and the worst values best which are represented with the italic values of each objective function values of each individual problem can be observed is given in Table 2.

Table 2. The pay-off table

\begin{tabular}{|l|c|c|c|}
\hline & $Z_{1}$ & $Z_{2}$ & $Z_{3}$ \\
\hline $\min Z_{1}$ & $20.628 .168,71$ & $5.541 .816,5$ & $41.247 .903,4$ \\
\hline $\max Z_{2}$ & 115.216 .765 .9 & $31.466 .018,7$ & 62.474 .292 .6 \\
\hline $\min Z_{3}$ & 118.686 .334 .7 & 27.697 .914 .29 & $26.993 .750,03$ \\
\hline The worst values & $118.686 .334,7$ & $5.541 .816,5$ & $62.474 .292,6$ \\
\hline
\end{tabular}

Considering the given values in Table 2, the membership functions are obtained as following:

$$
\begin{aligned}
& \mu_{1}\left(Z_{1}\right)=\left\{\begin{array}{cl}
1, & Z_{1}(x) \leq 20.628 .168,71, \\
\frac{118686334,7-Z_{1}(x)}{118686334,7-20.628 .168,71}, & 20.628 .168,71 \leq Z_{1}(x) \leq 118686334,7 ; \\
0, & Z_{1}(x) \geq 118686334,7,
\end{array}\right. \\
& \mu_{2}\left(Z_{2}\right)=\left\{\begin{array}{cl}
1, & Z_{2}(x) \geq 31.466 .018,7, \\
\frac{Z_{2}(x)-5.541 .816,5}{31.466 .018,7-5.541 .816,5}, & 5.541 .816,5 \leq Z_{2}(x) \leq 31.466 .018,7 ; \\
0, & Z_{2}(x) \leq 5.541 .816,5, \\
1, & Z_{3}(x) \leq 26.993 .750,03,
\end{array}\right. \\
& \mu_{3}\left(Z_{3}\right)=\left\{\begin{array}{cl}
\frac{0.474 .292,6-Z_{3}(x)}{62.474 .292,6-26.993 .750,03}, & 26.993 .750,03 \leq Z_{3}(x) \leq 62.474 .292,6 ; \\
0, & Z_{3}(x) \geq 62.474 .292,6 .
\end{array}\right.
\end{aligned}
$$

In the first phase, we calculate the minimal satisfactory for DMs by formulating the following problem:

maximize $\alpha$

subject to

$$
\begin{aligned}
& \alpha \leq \mu_{1}\left(Z_{1}\right)=\frac{118686334,7-Z_{1}(x)}{118686334,7-20.628 .168,71} ; \\
& \alpha \leq \mu_{2}\left(Z_{2}\right)=\frac{Z_{2}(x)-5.541 .816,5}{31.466 .018,7-5.541 .816,5} ; \\
& \alpha \leq \mu_{3}\left(Z_{3}\right)=\frac{62.474 .292,6-Z_{3}(x)}{62.474 .292,6-26.993 .750,03},
\end{aligned}
$$

constraints (11)-(47):

$0 \leq \alpha \leq 1$. 

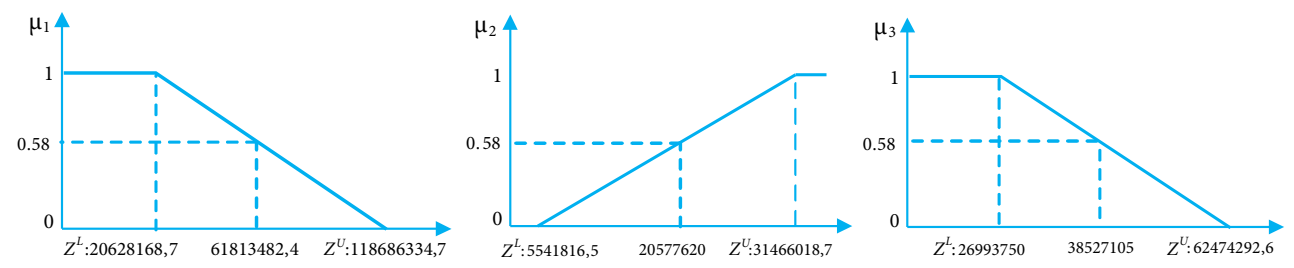

Fig. 3. Optimal objective values and membership function values

According to the optimal solution the minimal satisfactory level is obtained as 0.58 . The satisfaction levels of the other DMs are obtained as $\mu_{1}=\mu_{2}=\mu_{3}=\alpha$ respectively. Figure 3 shows the optimal objective values and membership function values.

\subsection{Solution by the Selim and Ozkarahan (2008)}

Linear programming problem is the first step of the algorithm. In the second step, each objective solved individually and the obtained pay-offs table relates to the objectives. The pay-off table indicates the best and worst values of the related objective function values of each individual problem can be observed is given in Table 2 which is above. Considering the values in the pay-off table, the best and worst values of the objective functions are obtained is given in Table 3 .

Table 3. The worst and the best values of objective functions relates to the problem

\begin{tabular}{|l|l|c|c|}
\hline & & Worst Value (\$) & Best Value (\$) \\
\hline Min & $Z_{1 \text { (Plants Objective) }}$ & $118.686 .334,74$ & $20.628 .168,71$ \\
\hline Max & $Z_{2 \text { (Dismantler Centers Objective) }}$ & $5.541 .816,50$ & $31.466 .018,70$ \\
\hline Min & $Z_{3 \text { (Customers Objective) }}$ & $62.474 .292,60$ & $26.993 .750,03$ \\
\hline
\end{tabular}

Considering the best and worst values given in Table 3 the membership functions are determined. Up to this point all steps are same as the Zimmermann's approach. In the next step, using a common satisfaction level $\gamma$ and the membership functions, the problem transforms into a single objective classic linear programming model as follows. $w_{1}=0.45, w_{2}=0.20$, $w_{3}=0.35$ is taken here.

maximize $\gamma+(1-\gamma) \cdot\left(0.45_{1}+0.20_{2}+0.35_{3}\right)$

subject to

$$
\begin{aligned}
& \mu_{1}(x)=\frac{118686334,7-Z_{1}(x)}{118686334,7-20.628 .168,71} \geq \lambda+\lambda_{1} ; \\
& \mu_{2}(x)=\frac{Z_{2}(x)-5.541 .816,5}{31.466 .018,7-5.541 .816,5} \geq \lambda+\lambda_{2} ; \\
& \mu_{3}(x)=\frac{62.474 .292,6-Z_{3}(x)}{62.474 .292,6-26.993 .750,03} \geq \lambda+\lambda_{3} ; \\
& \text { constraints }(11)-(47): \\
& 0 \leq, \gamma, \lambda_{1}, \lambda_{2}, \lambda_{3} \leq 1 .
\end{aligned}
$$


The results related to the different $\gamma$ values are given in Table 4 .

Table 4. The optimum values related to the different $\gamma$ values

\begin{tabular}{|c|c|c|c|c|c|c|c|c|c|c|}
\hline Gama & Alfa & $\begin{array}{c}\text { Obj. } \\
\text { Func. }\end{array}$ & $Z_{1}$ & $Z_{2}$ & $Z_{3}$ & $\mu_{1}$ & $\mu_{2}$ & $\mu_{3}$ & CPU & Total Cost \\
\hline 1 & 1 & 1 & 27705470,7 & 5760272 & 47675433,9 & 0,928 & 0,008 & 0,417 & 0,22 & 81141176,6 \\
\hline 0,8 & 1 & 0,73 & 28430773,6 & 7249716,3 & 38456499,1 & 0,92 & 0,066 & 0,677 & 0,28 & 74136989 \\
\hline 0,6 & 1 & 0,48 & 37680213,5 & 11185812,2 & 33871230,6 & 0,826 & 0,218 & 0,806 & 0,34 & 82737256,3 \\
\hline 0,4 & $*$ & 0,42 & 42558526,7 & 13208501,6 & 32529268,3 & 0,776 & 0,296 & 0,844 & 0,33 & 88296296,6 \\
\hline 0,2 & $*$ & 0,56 & 44728493,4 & 13706410,7 & 31784630,2 & 0,754 & 0,315 & 0,865 & 0,27 & 90219534,3 \\
\hline 0 & $*$ & 0,71 & 44536533,8 & 14456675 & 31701597,4 & 0,756 & 0,344 & 0,867 & 0,42 & 90694806,2 \\
\hline
\end{tabular}

\subsection{Solution by the Torabi and Hassini (2008)}

All calculations through the determination of the membership functions are the same as the Selim and Ozkarahan (2008) approach. The only difference is the transforming stage of the problem to one objective classic linear programming as mentioned above: $w_{1}=0.45$, $w_{2}=0.20, w_{3}=0.35$ are taken here as in the Selim and Ozkarahan (2008) solution. Torabi and Hassini's (2008) proposed formulation is as follows.

maximize $\gamma+(1-\gamma) \cdot\left(0.45_{1}+0.20_{2}+0.35_{3}\right)$

subject to

$$
\begin{aligned}
& \mu_{1}(x)=\frac{118686334,7-Z_{1}(x)}{118686334,7-20.628 .168,71} \geq \lambda ; \\
& \mu_{2}(x)=\frac{Z_{2}(x)-5.541 .816,5}{31.466 .018,7-5.541 .816,5} \geq \lambda ; \\
& \mu_{3}(x)=\frac{62.474 .292,6-Z_{3}(x)}{62.474 .292,6-26.993 .750,03} \geq \lambda . \\
& \text { constraints }(11)-(47): \\
& 0 \leq \alpha, \gamma, \lambda_{1}, \lambda_{2}, \lambda_{3} \leq 1 .
\end{aligned}
$$

The results related to different $\gamma$ values are given in Table 5 .

Table 5. The optimum values related to the different $\gamma$ values

\begin{tabular}{|c|c|c|c|c|c|c|c|c|c|c|}
\hline Gama & Alfa & $\begin{array}{c}\text { Obj. } \\
\text { Func. }\end{array}$ & $Z_{1}$ & $Z_{2}$ & $Z_{3}$ & $\mu_{1}$ & $\mu_{2}$ & $\mu_{3}$ & CPU & Total Cost \\
\hline 1 & 0,584 & 0,584 & 61389043,6 & 20689831,4 & 38556858,6 & 0,584 & 0,584 & 0,674 & 1,31 & 120635733,6 \\
\hline 0,8 & 0,579 & 0,6 & 61865242,5 & 20563935,9 & 31889822,5 & 0,579 & 0,579 & 0,862 & 0,66 & 114319000,9 \\
\hline 0,6 & 0,578 & 0,628 & 62046630,8 & 20515981,2 & 29312156,9 & 0,578 & 0,578 & 0,935 & 0,59 & 111874768,9 \\
\hline 0,4 & 0,569 & 0,644 & 62843436,5 & 20305325,1 & 29599166,6 & 0,569 & 0,569 & 0,927 & 0,34 & 112747928,2 \\
\hline 0,2 & 0,57 & 0,675 & 62804673,7 & 20315573,2 & 28899410,3 & 0,57 & 0,57 & 0,946 & 0,56 & 112019657,2 \\
\hline 0 & 0 & 0,71 & 43609499,1 & 13862366,5 & 32008170,7 & 0,766 & 0,321 & 0,859 & 0,38 & 89480036,3 \\
\hline
\end{tabular}




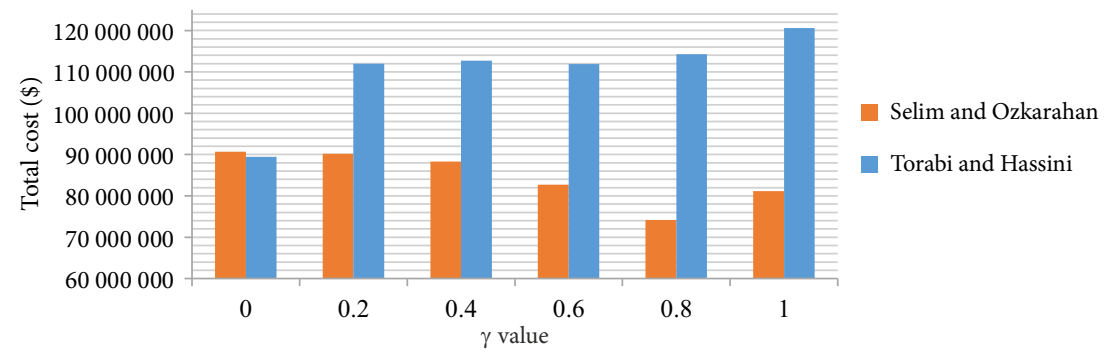

Fig. 4. Comparison of the effects of changing $\gamma$ values on total cost

According to the obtained results some implications are shown below:

- According to the Figure 4 total cost Selim and Ozkarahan (2008) (SO) and Torabi and Hassini (2008) (TH) approaches showed different behaviour when the $\gamma$ increased value. While increasing the $\gamma$ value, the total cost varies inversely.

- When $\gamma=0$ both methods give the nearest results with respect to total costs. Likewise when $\gamma=0.8$ the biggest difference is obtained between these two methods.

- In terms of the CPU times, the SO approach gives shorter times than TH approaches. An increase in $\gamma$ value decreases the CPU times of SO approach and increase the CPU times of TH approach.

- According to Figure 5 when we look at the impact of $\gamma$ values on satisfaction levels, while $\gamma=0$ the highest satisfaction level of both approaches is customers. The DM who has the lowest satisfaction level is the dismantler center which aims to maximize the profit. However, the plants satisfaction levels are close to each other.

- While increasing the $\gamma$ value, the satisfaction levels of customers and dismantler centers decrease but the plant satisfaction level increases for SO approach. Meanwhile, the same change occurs in the TH approaches for the customers, but for the other DMs, changes are different from the SO approach.

- According to the IFP approach, the SO method is more sensitive to $\gamma$ value than the TH method.

- According to Table 6, when $\gamma$ value is considered to be equal 0.4 for both methods, the total cost of the TH method is bigger than the SO method. However, the average satisfaction level of the TH method is higher than the SO method.

In Figure $5 \mu \mathrm{Zs}$ refers to SO approach and $\mu \mathrm{Zt}$ refers to $\mathrm{TH}$ approach.

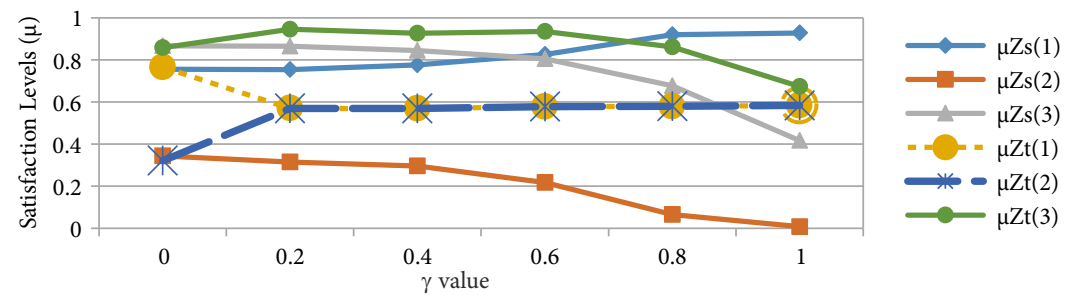

Fig. 5. Effect on satisfaction levels of the different $\gamma$ values 
Table 6. Comparison of the results for different approaches when $\lambda=0.4$

\begin{tabular}{|l|c|c|}
\hline & Selim and Özkarahan & Torabi and Hassini \\
\hline$Z_{1}$ & 42558526,70 & 62843436,50 \\
\hline$Z_{2}$ & 13208501,60 & 20305325,10 \\
\hline$Z_{3}$ & 32529268,30 & 29599166,60 \\
\hline Total Cost & 88296296,60 & 112747928,20 \\
\hline$\mu\left(Z_{1}\right)$ & 0,78 & 0,57 \\
\hline$\mu\left(Z_{2}\right)$ & 0,30 & 0,57 \\
\hline$\mu\left(Z_{3}\right)$ & 0,84 & 0,93 \\
\hline Average & 0,64 & 0,69 \\
\hline CPU(second) & 0,33 & 0,34 \\
\hline
\end{tabular}

\subsection{Solution by the Sakawa and Nishizaki (2002)}

Zimmermann approach described in the previous sections have been working under the assumption that multiple objectives to be optimized by a single DM (Paksoy, Özceylan 2013). However, as in real life, besides that, other decision problems can occur such as the multiple DMs has multiple objectives. Therefore, in this section we prefer the Sakawa and Nishizaki (2002) IFP approach. Assume that the minimal satisfactory level is not satisfying the upper level DMs and they specify the minimal satisfactory level $\hat{\delta}=0.65$ and formulate the following problem:

maximize $\alpha$

subject to

$$
\begin{aligned}
& \tilde{\delta}=0.65 \leq \mu_{1}\left(Z_{1}\right)=\frac{118686334,7-Z_{1}(x)}{118686334,7-20.628 .168,71}, \\
& \alpha \leq \mu_{2}\left(Z_{2}\right)=\frac{Z_{2}(x)-5.541 .816,5}{31.466 .018,7-5.541 .816,5}, \\
& \alpha \leq \mu_{3}\left(Z_{3}\right)=\frac{62.474 .292,6-Z_{3}(x)}{62.474 .292,6-26.993 .750,03} \\
& \text { constraints (11)-(47): } \\
& 0 \leq \alpha, \tilde{\delta} \leq 1
\end{aligned}
$$

DM0 sets the lower and the upper bounds of ratio $\Delta$ of satisfactory degree between both levels at 0.7 and 0.8 , respectively. The ratio of satisfactory degrees is in the specified interval the two levels is calculated as

$$
\Delta=\frac{\min (0.51,0.63)}{0.65}=\frac{0.51}{0.65}=0.78 \text {, so that he first phase of the IFP is finished. }
$$

At the second phase, the ratios of satisfaction between DM0s at the upper level and each of DM1 and DM2 at lower level are computed as according to the equation (54) in order to compare degrees of satisfaction of DM0 and each of DM1 and DM2 individually: 


$$
\Delta_{21}=\frac{\mu_{21}}{\mu_{11}}=\frac{0.51}{0.65}=0.78 ; \Delta_{22}=\frac{\mu_{22}}{\mu_{11}}=\frac{0.63}{0.65}=0.97 .
$$

DM0s determine the interval between the DM0s and DM1 as $\left[\Delta_{L}, \Delta_{U}\right]=[0.6,0.7]$, and $\mathrm{DM} 2\left[\Delta_{L}, \Delta_{U}\right]=[0.7,0.8]$.

While the DM2 and DM1 ratio is not in the interval. So that DM0 specifies the satisfactory levels at $\bar{\delta}=\tilde{\delta} \times \Delta_{U}^{21}=0,65 \times 0,7=0,455$ for the dismantler center and $\bar{\delta}=\tilde{\delta} \times \Delta_{U}^{22}=0,65 \times 0,8=0,52$ for the customer. The equation (54) with formulated as;

maximize $\alpha$

subject to

$$
\begin{aligned}
& \tilde{\delta}=0.65 \leq \mu_{1}\left(Z_{1}\right)=\frac{118686334,7-Z_{1}(x)}{118686334,7-20.628 .168,71}, \\
& \bar{\delta}=0.455 \leq \mu_{2}\left(Z_{2}\right)=\frac{Z_{2}(x)-5.541 .816,5}{31.466 .018,7-5.541 .816,5}, \\
& \bar{\delta}=0.52 \leq \mu_{3}\left(Z_{3}\right)=\frac{62.474 .292,6-Z_{3}(x)}{62.474 .292,6-26.993 .750,03} \\
& \text { constraints }(11)-(47): \\
& 0 \leq \alpha, \tilde{\delta}, \bar{\delta} \leq 1 .
\end{aligned}
$$

According to the equation (55) the optimal objective values and membership function values are shown in Figure 6.

At the last iteration, the ratio of satisfactory degrees between the DMs is in the specified interval.

$$
\Delta_{21}=\frac{\mu_{21}}{\mu_{11}}=\frac{0.455}{0.65}=0.7 ; \Delta_{22}=\frac{\mu_{22}}{\mu_{11}}=\frac{0.52}{0.65}=0.8 .
$$

Clearly seen that new satisfaction balance ratios are located between upper and lower limits $\Delta_{21}\left[\Delta_{L}, \Delta_{U}\right]=[0.6,0.7], \Delta_{22}\left[\Delta_{L}, \Delta_{U}\right]=[0.7,0.8]$.

Assuming that the upper-level DMs are happy with the new status, the process is terminated. At the end of the process satisfaction levels of plant, the dismantler center and the customer would be $65 \%, 45.5 \%$ and $52 \%$, respectively.
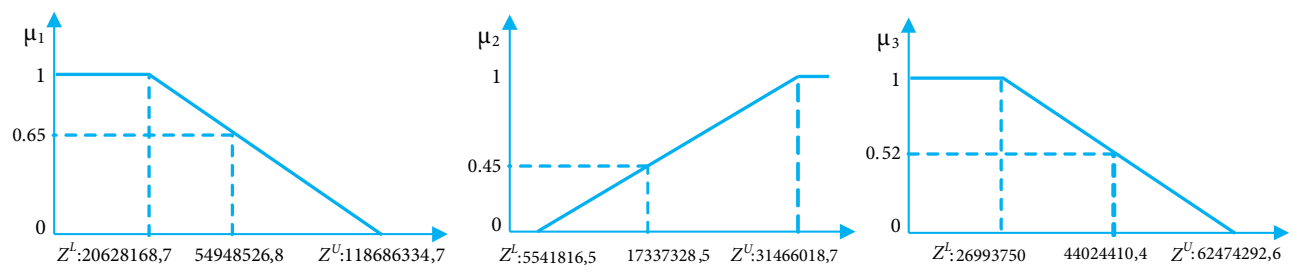

Fig. 6. Optimal objective values and membership function values for the new lower level satisfaction values 


\section{Conclusions}

The contribution of our work to the literature by: (i) developing an integrated, multi-level, multi-period, and multi-parts mixed-integer linear programming model to optimize the production and distribution planning for a CLSC network inspired by the automotive industry; (ii) transforming the heterogeneous flow in the network to homogenous flow with a weight ratio mechanism; (iii) considering purchasing (raw material) and refurbishing (used-parts/ products) costs that will be most economically and environmentally effective in managing the realistic trade-off problem; (iv) presenting the results of four different IFP-approached computational experiments that shed light on the interactions of various performance indicators, applying the proposed model to a sample problem instance; (v) showing that SO method is more sensitive to value than TH method; (vi) Sakawa and Nishizaki (2002) approach outperforms the Zimmerman (1978) approach in terms of satisfaction levels of upper level DM. Computational experiments are carried out for the proposed CLSC model which is inspired by the automotive industry and these IFP approaches are compared to develop some managerial implications for CLSC managers.

Our model was inspired by the Turkish automotive industry and this is a generic model. This model reflects the main attributes of the sector of the automotive industry, thus practitioners and academicians can easily apply this model to their studies. Due to the fact that the automotive production systems include lots of parts and suppliers, we proposed a mathematical formulation that includes a bill of materials which reflects the complexity of CLSC system more reliably. According to this model we showed the heterogeneous flow in the network is transformed to the homogenous flow by a weight ratio mechanism. And this is one of the pioneering studies in this area.

According to the Sakawa and Nishizaki (2002) approach, the increase of the satisfaction level of upper level DM causes a major decrease of the satisfaction level of the dismantler center. The main reason for this change is that the objective of the plants and the objective of the dismantler centers conflict.

For future research, a heuristic procedure should be developed to solve the proposed NPhard mixed-integer programming model. Also, Fuzzy, Grey theory and stochastic modelling approaches should be applied to solve the embedded uncertainty in demand and reverse rates to facilitate practical applications. Furthermore, some ideas can be applied in case of nonlinearity to the model such as Newton's methods and other methods of the Newton family: Quasi-Newton methods, Successive Orthogonal Projections (S.O.P.) methods, and Trust Region Algorithms.

\section{Acknowledgements}

In carrying out this study the corresponding author (T. Paksoy) is granted by the Scientific and Technological Research Council of Turkey (TUBITAK) (International Postdoctoral Research Fellowship Program). This fund is hereby gratefully acknowledged. 


\section{References}

Abd El-Wahed, W. F.; Lee, S. M. 2006. Interactive fuzzy goal programming for multi-objective transportation problems, Omega 34: 158-166. https://doi.org/10.1016/j.omega.2004.08.006

Azevedo, S. G.; Carvalho, H.; Cruz, Machado, V. 2011. The influence of green practices on Supply Chain performance: a case study approach, Transportation Research Part E: Logistics and Transportation Review 47(6): 850-871. https://doi.org/10.1016/j.tre.2011.05.017

Baenas, J. M. H.; Castro, R. de.; Battistelle, R. A. G.; Junior, J. A. G. 2011. A study of reverse logistics flow management in vehicle battery industries in the Midwest of the state of São Paulo (Brazil), Journal of Cleaner Production 19(2-3): 168-172. https://doi.org/10.1016/j.jclepro.2010.08.018

Bilgen, B. 2010. Application of fuzzy mathematical programming approach to the production allocation and distribution supply chain network problem, Expert Systems with Applications 37(6): 4488-4495. https://doi.org/10.1016/j.eswa.2009.12.062

Cruz-Rivera, R.; Ertel, J. 2009. Reverse logistics network design for the collection of end-of-life vehicles in Mexico, European Journal of Operational Research 196: 930-939.

https://doi.org/10.1016/j.ejor.2008.04.041

Demirel, N. Ö.; Gökçen, H. 2008. A mixed integer programming model for remanufacturing in reverse logistics environment, The International Journal of Advanced Manufacturing Technology 39(11-12): 1197-1206. https://doi.org/10.1007/s00170-007-1290-7

Farahani, R. Z.; Rezapour, S.; Drezner, T.; Fallah, S. 2014. Competitive supply chain network design: an overview of classifications, models, solution techniques and applications, Omega 45: 92-118. https://doi.org/10.1016/j.omega.2013.08.006

Harraz, N. A.; Galal, N. M. 2011. Design of sustainable end-of-life vehicle recovery network in Egypt, Ain Shams Engineering Journal 2(3-4): 211-219. https://doi.org/10.1016/j.asej.2011.09.006

Kanari, N.; Pineau, J-L.; Shallari, S. 2003. End-of-life vehicle recycling in the European Union [online], [cited 05 January 2015]. Available from Internet: http://www.tms.org/pubs/journals/JOM/0308/ Kanari-0308.html

Kumar, V.; Sutherland, J.-W. 2008. Sustainability of the automotive recycling infrastructure: review of current research and identification of future challenges, International Journal of Sustainable Manufacturing 1(1/2): 145-167. https://doi.org/10.1504/IJSM.2008.019231

Liang, T. F. 2006. Distribution planning decisions using interactive fuzzy multi-objective linear programming, Fuzzy Sets and Systems 157(10): 1303-1316. https://doi.org/10.1016/j.fss.2006.01.014

Mahmoudzadeh, M.; Mansour, S.; Karimi, B. 2013. To develop a third-party reverse logistics network for end-of-life vehicles in Iran, Resources, Conservation and Recycling 78: 1-14. https://doi.org/10.1016/j.resconrec.2013.06.006

Mirakhorli, A. 2014. Fuzzy multi-objective optimization for closed loop logistics network design in bread-producing industries, International Journal of Advanced Manufacturing Technology 70: 349362. https://doi.org/10.1007/s00170-013-5264-7

Neto, J. Q. F.; Bloemhof-Ruwaard, J. M.; Van Nunen, J. A. E. E.; Van Heck, E. 2008. Designing and evaluating sustainable logistics networks, International Journal of Production Economics 111(2): 195-208. https://doi.org/10.1016/j.ijpe.2006.10.014

Özceylan, E.; Paksoy, T. 2012. A mixed integer programming model for a closed-loop supply chain network, International Journal of Production Research 51(3): 718-734.

https://doi.org/10.1080/00207543.2012.661090

Özceylan, E.; Paksoy, T.; Bektaş, T. 2014. Modeling and optimizing the integrated problem of closedloop supply chain network design and disassembly line balancing, Transportation Research Part E 6: 142-164. https://doi.org/10.1016/j.tre.2013.11.001 
Paksoy, T.; Özceylan, E. 2013. An interactive fuzzy programming approach for a decentralized closedloop supply chain network design problem, in $26^{\text {th }}$ European Conference on Operational Conference, 1-3 July 2013, Rome, Italy, Abstract book: 65.

Pishvaee, M. S.; Torabi, S. A. 2010. A possibilistic programming approach for closed-loop supply chain network design under uncertainty, Fuzzy Sets and Systems 161(20): 2668-2683.

https://doi.org/10.1016/j.fss.2010.04.010

Qu, X.; Williams, J. A. S. 2008. An analytical model for reverse automotive production planning and pricing, European Journal of Operational Research 190: 756-767. https://doi.org/10.1016/j.ejor.2007.06.041

Sakawa, M.; Nishizaki, I. 2002. Interactive fuzzy programming for decentralized two-level linear programming problems, Fuzzy Sets and Systems 125(3): 301-315.

https://doi.org/10.1016/S0165-0114(01)00042-2

Sakawa, M.; Nishizaki, I.; Uemura, Y. 1998. Interactive fuzzy programming for multilevel linear programming problems, Computers \& Mathematics with Applications 36(2): 71-86. https://doi.org/10.1016/S0898-1221(98)00118-7

Salema, M. I. G.; Barbosa-Povoa, A. P.; Novais, A. Q. 2007. An optimization model for the design of a capacitated multi-product reverse logistics network with uncertainty, European Journal of Operational Research 179(3): 1063-1077. https://doi.org/10.1016/j.ejor.2005.05.032

Sasikumar, P.; Haq, A. N. 2010. Analysing interactions among battery recycling barriers in the reverse supply chain, in L. Wang, S. Koh (Eds.). Enterprise Networks and Logistics for Agile Manufacturing. Springer, London, 249-269. https://doi.org/10.1007/978-1-84996-244-5_12

Schultmann, F.; Zumkeller, M.; Rentz, O. 2006. Modelling reverse logistic tasks within closed-loop supply chains: an example from the automotive industry, European Journal of Operational Research 171(3): 1033-1050. https://doi.org/10.1016/j.ejor.2005.01.016

Selim, H.; Araz, C.; Özkarahan, I. 2008. Collaborative production-distribution planning in supply chain: a fuzzy goal programming approach, Transportation Research Part E 44(3): 396-419. https://doi.org/10.1016/j.tre.2006.11.001

Selim, H.; Ozkarahan, İ. 2008. A supply chain distribution network design model: an interactive fuzzy goal programming-based solution approach, International Journal of Advanced Manufacturing Technology 36(3-4): 401-418. https://doi.org/10.1007/s00170-006-0842-6

Staudinger, J.; Keoleian, G. A.; Flynn, M. S. 2001. Management of end-of-life vehicles (ELVs) in the US. Report for Japan External Trade Organization (JETRO), University of Michigan Centre for Sustainable Systems Report No CSS01-01 Ann Arbor MI.

Subulan, K.; Tasan, A. S.; Baykasoğlu, A. 2015a. A fuzzy goal programming model to strategic planning problem of a lead/acid battery closed-loop supply chain, Journal of Manufacturing Systems 37 Part 1: 243-264. https://doi.org/10.1016/j.jmsy.2014.09.001

Subulan, K.; Tasan, A. S.; Baykasoğlu, A. 2015b. Designing an environmentally conscious tire closedloop supply chain network with multiple recovery options using interactive fuzzy goal programming, Applied Mathematical Modelling 39(9): 2661-2702. https://doi.org/10.1016/j.apm.2014.11.004

Tang, Q.; Xie, F. 2007. A genetic algorithm for reverse logistics network design, in ICNC '07 Proceedings of the Third International Conference on Natural Computation, 24-27 August 2007, 4: 277-281.

Torabi, S. A.; Hassini, E. 2008. An interactive possibilistic programming approach for multiple objective supply chain master planning, Fuzzy Sets and Systems 159(2): 193-214. https://doi.org/10.1016/j.fss.2007.08.010

Vahdani, B.; Moghaddam, R. T.; Modarres, M.; Baboli, A. 2012. Reliable design of a forward/reverse logistics network under uncertainty: a robust-M/M/c queuing model, Transportation Research Part E: Logistics and Transportation Review 48(6): 1152-1168. https://doi.org/10.1016/j.tre.2012.06.002 
Vidovic, M.; Dimitrijevic, B.; Ratkovic, B.; Simic, V. 2011. A novel covering approach to positioning ELV collection points, Resources, Conservation and Recycling 57: 1-9. https://doi.org/10.1016/j.resconrec.2011.09.013

Wang, H.-F.; Hsu, H.-W. 2010. A closed-loop logistic model with a spanning-tree based genetic algorithm, Computers and Operations Research 37(2): 376-389. https://doi.org/10.1016/j.cor.2009.06.001

Williams, J. A. S.; Wongweragiat, S.; Qu, X.; McGlinch, J. B.; Bonawi-tan, W.; Choi, J. K.; Schiff, J. 2007. An automotive bulk recycling planning model, European Journal of Operational Research 177: 969-981. https://doi.org/10.1016/j.ejor.2006.01.031

Zarandi, M. H.; Sisakht, A. H.; Davari, S. 2011. Design of a closed-loop supply chain (CLSC) model using an interactive fuzzy goal programming, The International Journal of Advanced Manufacturing Technology 56(5): 809-821. https://doi.org/10.1007/s00170-011-3212-y

Zarei, M.; Mansour, S.; Kashan, A. H.; Karimi, B. 2010. Designing a reverse logistics network for endof-life vehicles recovery, Mathematical Problems in Engineering. Article ID 649028.

Zhou, Y.; Xiong, Y.; Li, G., Xiong, Z.; Beck, M. 2013. The bright side of manufacturing-remanufacturing conflict in a decentralized closed-loop supply chain, International Journal of Production Research 51(9): 2639-2651. https://doi.org/10.1080/00207543.2012.737956

Zimmermann, H. J. 1978. Fuzzy programming and linear programming with several objective functions, Fuzzy Sets and Systems 1(1): 45-55. https://doi.org/10.1016/0165-0114(78)90031-3 